\title{
Learning Management System (LMS) among University Students: Does It Work?
}

\begin{abstract}
The Learning Management System (LMS) has been established in a number of universities worldwide to help connect students and lecturers without the confines of the traditional classroom. It is an environment with digital software which is designed to manage user learning interventions as well as deliver learning content and resources to students. Since the LMS system has already been implemented and it has also been made compulsory for the lecturers to apply in their daily lectures, it is vital to identify feedback of students as users of LMS. Previous studies have shown various findings in relation to the impact of using LMS in the higher learning environment in various universities worldwide. Therefore, this paper will provide several insights of the LMS phenomenon.
\end{abstract}

Keyword: Learning management systems; Higher learning; Content; Acceptance; Impact; Worldwide. 